\title{
Global and Specific Motor Inhibitory Mechanisms during Action Preparation
}

\author{
Caroline Quoilin and Gerard Derosiere \\ Cognition and Actions Laboratory, Institute of Neuroscience, Université Catholique de Louvain, 1200 Brussels, Belgium \\ Review of Greenhouse et al.
}

Understanding the neural mechanisms that enable people to choose and perform appropriate actions when pursuing a goal is an intricate challenge for contemporary neuroscience. This human behavior is thought to rely in part on excitatory influences increasing the neural activity associated with each potential action, but also on inhibitory mechanisms modulating the related motor representations ( $\mathrm{Mu}-$ rakami and Mainen, 2015). Indeed, recent behavioral and electrophysiological studies have revealed that the primary motor cortex is transiently inhibited when preparing an action (Tandonnet et al., 2011; Labruna et al., 2014). What is the function of these inhibitory influences during action preparation?

Based on a collection of empirical findings (for review, see Bestmann and Duque, 2015), it has been proposed that motor inhibition during action preparation reflects the co-occurrence of two different mechanisms. On the one hand, a reduction of corticospinal excitability has been reported in effectors that are not selected for the forthcoming action, but which are part of the alternative response options-leading to the suggestion of a mechanism referred to as "competition resolution"

Received Oct. 5, 2015; revised Nov. 4, 2015; accepted Nov. 10, 2015. The authors declare no competing financial interests.

Correspondence should be addressed to Dr. Caroline Quoilin, Cognition and Actions Laboratory, Institute of Neuroscience, Université Catholique de Louvain, Ave Mounier 53, Bte B1.53.04, 1200 Brussels, Belgium. E-mail: caroline.quoilin@uclouvain.be.

DOI:10.1523/JNEUROSCI.3664-15.2015

Copyright $\odot 2015$ the authors $\quad 0270-6474 / 15 / 3516297-03 \$ 15.00 / 0$
(Duque et al., 2010, 2012). Such a process would help ensure the desired action is selected by suppressing the alternative options, possibly through modulation of mutual inhibitory interactions between representations of potential actions (Labruna et al., 2014). On the other hand, inhibition has also been recorded in muscles required to perform the planned action. This suppression of activity would rely on a second mechanism called "impulse control," which would aim at preventing actions from being released prematurely (Duque et al., 2010; 2012).

In a recent paper in The Journal of $\mathrm{Neu}$ roscience, Greenhouse et al. (2015b) further explored the functional significance of preparatory inhibition through three separate experiments. Single-pulse transcranial magnetic stimulation (TMS) was applied over the right primary motor cortex when subjects were performing a simple or a choice reaction-time task (SRT and CRT tasks, respectively). In the CRT task, subjects had to respond with the left or the right index finger depending on an informative cue they were shown. In contrast, selection was not required in the SRT task, as only one type of cue was presented within a block. Consequently, while both fingers were potential responders in the CRT task, only one index finger was relevant for the SRT task. TMSinduced motor-evoked potentials (MEPs) were recorded in the left first dorsal interosseous (FDI) muscle either at baseline or during a delay period, i.e., when participants were preparing to make a specific movement based on the informative cue, but had to withhold their response until an imperative signal was given. As MEP amplitudes depend on the level of corticospinal excitability in specific motor representations, inhibition targeted at either selected or nonselected muscles would be reflected by smaller MEPs in these muscles during the delay period (i.e., compared with baseline).

Overall, the results in the CRT task were in agreement with previous studies using the same type of paradigm (Duque and Ivry, 2009; Duque et al., 2010; Lebon et al., 2015). That is, left FDI MEPs recorded during the delay period were suppressed when either the left or the right hand was cued for the forthcoming response, confirming the presence of inhibition in both selected and nonselected hands during action preparation. Most importantly, these results extended previous research by revealing a significant MEP suppression in the left FDI muscle when subjects had only to respond with the right hand in the SRT task. Hence, preparatory inhibition was reported in a task-irrelevant muscle outside the context of an action choice. Based on these findings, the authors question the relevance of the dual model of inhibition described above, upholding that neither the competition resolution nor the impulse control can explain the reduction of MEP amplitudes in a task-irrelevant muscle observed in the SRT task. Instead, they propose a unitary model of motor inhibitory changes during action preparation. 
According to this hypothesis, inhibition broadly influences the motor system during action preparation, targeting all motor representations regardless of their relevance for the task.

The proposition of a unitary model of preparatory inhibition is extremely interesting and fairly accounts for the new findings made by Greenhouse et al. (2015b). In fact, compared with the dual model, the unitary model could better explain the observation of inhibition in muscles that are outside the range of alternative response options. As such, an inhibitory process would be solicited as soon as an action has to be prepared, whether or not this preparation requires selecting among different action options. Importantly, the strength of this global inhibition is likely to be influenced by the difficulty of the task, which might notably increase with the need to choose between several actions, the presence of conflict, or the complexity of movements to be performed (Klein et al., 2014; Greenhouse et al., 2015a).

Yet, contrary to what Greenhouse et al. (2015b) suggest in their article, their findings do not exclude the existence of additional inhibitory mechanisms during action preparation, such as those described by the dual model. In fact, in the CRT task, greater MEP suppression was reported for the hand selected for the forthcoming movement relative to the nonselected one. The authors explained this difference by specifying that the global preparatory inhibition they observed might function as a spotlight centered on the selected cortical motor representation. Although attractive, this hypothesis could be considered as a mere alternative interpretation of their data, which does not invalidate the co-occurrence of multiple inhibitory mechanisms during action preparation. In fact, albeit not discussed by the authors, other works on the neurophysiological underpinnings of MEP changes in selected and nonselected muscles strongly suggest the existence of multiple inhibitory mechanisms. Indeed, higher cortical activity in a selected motor representation (i.e., compared with a nonselected motor representation) has been observed despite peripheral MEP suppression, suggesting that excitability of selected responses is modulated beyond the cortex in this specific condition (Duque et al., 2012). Accordingly, a reduction of Hoffman-reflexes, which provide a measure of spinal excitability, has been specifically reported in selected hand muscle representations (Hasbroucq et al., 1999; Duque et al., 2010). Moreover, whereas a virtual lesion to the lateral pre- frontal cortex reduces MEP suppression in both selected and nonselected effectors, supporting the involvement of this area in a nonspecific motor inhibition mechanism, a virtual lesion to the dorsal premotor cortex specifically affects MEP suppression in the selected effector, suggesting a distinct source for the inhibition observed in that effector (Duque et al., 2012). Hence, it is reasonable to assume that a specific inhibitory mechanism, which would selectively reduce the activity of selected responses at the spinal level, would occur in parallel with the global process proposed by Greenhouse et al. (2015b). While the latter inhibitory mechanism would broadly influence the motor system during action preparation, the former would be targeted at selected motor representations and could further explain the spotlight-shaped inhibition observed by Greenhouse et al. (2015b). Of note, both global (Snyder and Foxe, 2010) and specific (Kelly et al., 2006) processes have already been identified in other fields, notably in research on inhibition of the visual system during selective attention. Based on the functional and anatomical similarities between the visual and the motor neural structures (Friston, 2005), a comparable existence of multiple forms of inhibition within the motor system during response preparation would not be startling.

Alternatively, the strong inhibition observed in task-irrelevant muscles during the SRT task in Greenhouse et al. (2015b) could be due to the inclusion of a relatively large amount of catch trials. Small numbers of these trials are typically included to prevent participants from initiating their response before the imperative signal but they rarely account for $>5-8 \%$ of trials (Duque and Ivry, 2009; Duque et al., 2012). In contrast, in Greenhouse et al. (2015b), almost $20 \%$ of trials in the SRT and CRT blocks were catch trials. Consequently, the observed MEP suppression in task-irrelevant muscles may have been related to processes recruited in anticipation of the need to abort the prepared action in the presence of a catch signal rather than reflecting preparatory inhibition. The neural processes associated with such stopping behavior is typically assessed through Go/No-Go and stopsignal tasks, in which participants have to suppress their response after the presentation of a specific cue, which occurs in $\sim 25 \%$ of trials (Verbruggen and Logan, 2008). Successful performance on such tasks has been shown to rely on global inhibitory effects on the motor system (Badry et al., 2009; Wessel et al., 2013). Therefore, the high number of catch trials used in Greenhouse et al. (2015b) may have led participants to anticipate the potential need to withhold their response, which resulted in a global inhibitory effect. In agreement with this hypothesis, MEP suppression in task-irrelevant muscles was not reported in the absence of catch trials (Duque et al., 2010). Finally, although the impact of catch trials was addressed in Greenhouse et al. (2015b), it only concerned relevant muscles in a CRT task, which is not the experimental condition used by the authors to draw their conclusions (i.e., a SRT task). To clarify this point, future research should involve within-subject comparisons of MEP suppression during stop-signal and instructeddelay SRT tasks.

In conclusion, the work by Greenhouse et al. (2015b) relaunches the question of the functional significance of inhibitory processes at play during action preparation in humans. Based on their findings, the authors propose a new model of motor inhibition, putting the emphasis on the global nature of inhibitory changes during action preparation. On this basis, and in accordance with previous studies, we discussed the possible co-occurrence of separate processes exerting both global and specific influences over the motor system during action preparation. The current study opens the way toward future research projects aiming to better understand the specificity of neurophysiological mechanisms underlying different facets of motor inhibition, such as the ones involved in action preparation and action stopping.

\section{References}

Badry R, Mima T, Aso T, Nakatsuka M, Abe M, Fathi D, Foly N, Nagiub H, Nagamine T, Fukuyama H (2009) Suppression of human cortico-motoneuronal excitability during the stop-signal task. Clin Neurophysiol 120:17171723. CrossRef Medline

Bestmann S, Duque J (2015) Transcranial magnetic stimulation decomposing the processes underlying action preparation. Neuroscientist. Advance online publication. Retrieved July 10, 2015. doi:10.11177/1073858415592 594. CrossRef Medline

Duque J, Ivry RB (2009) Role of corticospinal suppression during motor preparation. Cereb Cortex 19:2013-2024. CrossRef Medline

Duque J, Lew D, Mazzocchio R, Olivier E, Ivry RB (2010) Evidence for two concurrent inhibitory mechanisms during response preparation. J Neurosci 30:3793-3802. CrossRef Medline

Duque J, Labruna L, Verset S, Olivier E, Ivry RB (2012) Dissociating the role of prefrontal and premotor cortices in controlling inhibitory mechanisms during motor preparation. J Neurosci 32:806-816. CrossRef Medline

Friston K (2005) A theory of cortical responses. Philos Trans R Soc Lond B Biol Sci 360: 815-836. CrossRef Medline 
Greenhouse I, Saks D, Hoang T, Ivry RB (2015a) Inhibition during response preparation is sensitive to response complexity. J Neurophysiol 113:2792-2800. CrossRef Medline

Greenhouse I, Sias A, Labruna L, Ivry RB (2015b) Nonspecific inhibition of the motor system during response preparation. J Neurosci 35: 10675-10684. CrossRef Medline

Hasbroucq T, Kaneko H, Akamatsu M, Possamaï CA (1999) The time-course of preparatory spinal and cortico-spinal inhibition: an H-reflex and transcranial magnetic stimulation study in man. Exp Brain Res 124:33-41. CrossRef Medline

Kelly SP, Lalor EC, Reilly RB, Foxe JJ (2006) Increases in alpha oscillatory power reflect an active retinotopic mechanism for distracter suppression during sustained visuospatial attention. J Neurophysiol 95:3844-3851. CrossRef Medline

Klein PA, Petitjean C, Olivier E, Duque J (2014)
Top-down suppression of incompatible motor activations during response selection under conflict. Neuroimage 86:138-149. CrossRef Medline

Labruna L, Lebon F, Duque J, Klein PA, Cazares C, Ivry RB (2014) Generic inhibition of the selected movement and constrained inhibition of nonselected movements during response preparation. J Cogn Neurosci 26: 269-278. CrossRef Medline

Lebon F, Greenhouse I, Labruna L, Vanderschelden B, Papaxanthis C, Ivry RB (2015) Influence of delay period duration on inhibitory processes for response preparation. Cereb Cortex. Advance online publication. Retrieved April 16, 2015. doi:10.1093/cercor/ bhv069. CrossRef Medline

Murakami M, Mainen ZF (2015) Preparing and selecting actions with neural populations: toward cortical circuit mechanisms. Curr Opin Neurobiol 33:40-46. CrossRef Medline
Snyder AC, Foxe JJ (2010) Anticipatory attentional suppression of visual features indexed by oscillatory alpha-band power increases: a high-density electrical mapping study. J Neurosci 30:4024-4032. CrossRef Medline

Tandonnet C, Garry MI, Summers JJ (2011) Selective suppression of the incorrect response implementation in choice behavior assessed by transcranial magnetic stimulation. Psychophysiology 48:462-469. CrossRef Medline

Verbruggen F, Logan GD (2008) Automatic and controlled response inhibition: associative learning in the go/no-go and stop-signal paradigms. J Exp Psychol Gen 137:649-672. CrossRef Medline

Wessel JR, Reynoso HS, Aron AR (2013) Saccade suppression exerts global effects on the motor system. J Neurophysiol 110:883-890. CrossRef Medline 